\title{
MACHADO DE ASSIS E O SEU QUINTETO CARIOCA
}

Ensaio transcrito a partir da publicação em SENA, Jorge. Estudos de Cultura e Literatura Brasileira. Lisboa: Edições 70, 1988. p. 325-335.

\section{JORGE DE SENA}

\author{
APRESENTAÇÃO DE HÉLIO DE SEIXAS GUIMARÃES \\ Universidade de São Paulo \\ São Paulo, São Paulo, Brasil
}

Resumo: O ensaio trata da obra de Machado de Assis em duas direções: por um lado, apresenta uma reflexão sobre as dificuldades generalizadas de posicionamento e classificação do escritor genial que produziu sua obra à margem dos países que se colocam como centro mundial da cultura; de outro, analisa os cinco últimos romances do escritor, considerando-os como uma unidade estética, construída em torno de Dom Casmurro. As duas linhas de abordagem confluem para uma única pergunta - como terá sido possível alcançar tal complexidade numa literatura nascente? - à qual Jorge de Sena procura dar resposta.

Palavras-chave: romance; realismo; literatura menor.

\section{MACHADO DE ASSIS AND HIS CARIOCA QUINTET}

\begin{abstract}
This essay addresses Machado de Assis's work in two ways: it presents a reflection on the overall challenges of positioning and classifying the ingenious writer who produced his work on the margins of countries held to be at the center of the world culture on the one hand and analyzes the writer's last five novels as an aesthetic unit centered around Dom Casmurro on the other. Both approaches converge on one question - how was it possible to achieve such complexity in a rising literature? which Jorge de Sena seeks to answer.
\end{abstract}

Keywords: novel; realism; minor literature.

Autor de extensa obra poética, romancista, autor de teatro, crítico literário prolífico, missivista incansável, tradutor, Jorge de Sena foi uma das 
figuras mais destacadas e influentes das relações entre Brasil, Portugal e Estados Unidos no século XX.

O conjunto dos seus escritos compreende nada menos que vinte coletâneas de poesia, uma tragédia em verso, uma dezena de peças, mais de trinta contos, uma novela e um romance, além de cerca de quarenta volumes dedicados à crítica e ao ensaio, entre eles uma coletânea de ensaios sobre literatura brasileira, no qual foi coligido o texto reproduzido neste número da Machado de Assis em linha.

Engenheiro formado pela Universidade do Porto, Sena trabalhou na profissão por mais de dez anos, até 1959, quando se exilou no Brasil por motivos políticos, fugindo da perseguição da ditadura salazarista.

A mudança para o Brasil significou também a dedicação a um novo ofício - o ensino de literatura -, que exerceria até o final da vida. Em 1964, doutorou-se em Letras na Faculdade de Filosofia, Ciências e Letras de Araraquara, onde também se tornou livre-docente. Atuou ainda na Faculdade de Letras de Assis, onde travou com Dante Moreira Leite e Antonio Candido amizades que manteria ao longo de toda vida.

Nos seis anos em que viveu no Brasil, teve intensa produção artística e intelectual. Nesse período escreveu poemas que integraram o volume Metamorfoses, a novela $O$ físico prodigioso, começou a escrever o romance Sinais de fogo e publicou ensaios importantes sobre Camões e Pessoa, dedicando-se também aos estudos sobre o Maneirismo, assunto do qual era grande conhecedor.

Pouco depois do golpe militar de 1964, recebeu convite para lecionar nos Estados Unidos, transferindo-se em 1965 para lá, com Mécia de Sena e os nove filhos do casal. Passou a lecionar na Universidade de Wisconsin, em Madison, um dos grandes centros dos estudos luso-brasileiros nos Estados Unidos, fundado por Lloyd A. Kasten ainda na década de 1930. Nos cinco anos em que atuou em Madison, promoveu intenso intercâmbio com intelectuais brasileiros, fazendo daquela universidade também um polo de estudos sobre Machado de Assis.

Em 1967, a convite de Jorge de Sena, Dante Moreira Leite ministrou em Madison um curso de pós-graduação sobre Machado de Assis. Em maio de 1968, Antonio Candido esteve na universidade para uma palestra que viria a ser publicada com o título "Esquema de Machado de Assis". Esse ensaio, incluído em Vários escritos (1970), fazia uma síntese dos principais estudos machadianos realizados até aquele momento, propunha novas chaves de 
interpretação para a obra e tornava-se referência importante para os estudos sobre Machado de Assis.

Foi nessa atmosfera de intensas trocas intelectuais com seus pares portugueses e brasileiros que Sena escreveu "Machado de Assis e o seu quinteto carioca", reproduzido nesta edição. Em sintonia com o que então era publicado sobre teoria literária e crítica machadiana, Sena defendia uma leitura mais integradora da obra de Machado de Assis, assim como fizera Silviano Santiago em seu "Retórica da verossimilhança", ao afirmar: "Já é tempo de se começar a compreender a obra de Machado de Assis como um todo coerentemente organizado, percebendo que à medida que seus textos se sucedem cronologicamente certas estruturas primárias e primeiras se desarticulam sob forma de estruturas diferentes, mais complexas e mais sofisticadas" (SANTIAGO, 2000, p. 27).

No seu ensaio, Sena debruça-se especialmente sobre os cinco últimos romances publicados por Machado de Assis, defendendo uma hipótese fecunda: a da conexão profunda entre os cinco últimos romances - Memórias póstumas de Brás Cubas, Quincas Borba, Dom Casmurro, Esaú e Jacó e Memorial de Aires, que lhes dariam uma "unidade estética". Na argumentação do ensaísta, o eixo central do quinteto estaria em Dom Casmurro, em torno do qual se teceriam as outras histórias.

$O$ ensaio revela também uma aguda sensibilidade para a incidência das questões geopolíticas sobre o estudo de língua e literatura. Sena mostra, a partir do exame do caso Machado de Assis, como os grandes escritores de línguas consideradas menores, ou periféricas, situação da língua portuguesa no contexto norte-americano, são tratados como "pequenos gênios exóticos", dificilmente postos em pé de igualdade com os grandes escritores das culturas consideradas "grandes".

Em 1970, Jorge de Sena transferiu-se para a Universidade da Califórnia, em Santa Bárbara, onde foi professor catedrático de Literatura Portuguesa e Brasileira e de Literatura Comparada. Na mesma universidade, tornou-se chefe do Departamento de Espanhol e Português, cargo que ocupava por ocasião da sua morte precoce, aos 58 anos, em 1978.

A Machado de Assis em linha, honrada por publicar o ensaio de Jorge de Sena, agradece aos seus herdeiros, por meio da filha Isabel de Sena, a autorização para publicação. Agradece também a Élide Valarini Oliver, da Universidade da Califórnia, em Santa Bárbara, pela intermediação. 
ste estudo não pretende ser uma proposta de revisão e correção de alguns pontos de vista demasiado aceites sobre Machado de Assis, mas uma tentativa de apresentar os cinco grandes romances da sua última fase como um todo, e, mesmo mais, como uma unidade estética, em termos de moderna técnica de ficção novelística. Nesse "Quinteto", Dom Casmurro, publicado há setenta anos, e considerado o mais belo romance de Machado (e por certo uma das obras-primas com que o século XIX encerrou cronologicamente uma universal e gloriosa criação do romance como género por excelência), ocupa e define o eixo central do conjunto.

É apanágio das culturas que se sentem ou supõem marginais em relação às "grandes" (ou sejam, no Ocidente, aquelas que primeiro se impuseram politicamente à Europa e ao mundo da nossa história moderna) a circunstância de produzirem escritores peculiarmente grandes, mesmo maiores do que a comum medida de grandeza das "grandes" (excluídos os Dantes e os Shakespeares que não servem de medida para coisa nenhuma, nem mesmo nas literaturas a que pertencem), mas que sofrem, na sua grandeza, de uma tripla condição infeliz. Internacionalmente, o prestígio das grandes culturas e a incapacidade delas para verem ou aceitarem algo fora de si mesmas impede que lhes seja reconhecida mais que a categoria de curiosos pequenos génios exóticos, por definição menores que os das reconhecidas culturas. Que haja, no seio das grandes culturas, personalidades que os proclamem, dado que têm amor por essa pequena cultura a que tais escritores grandes pertençam, em nada altera a condição descrita, pois que essas personalidades não terão quase nunca, dentro das grandes culturas em que surjam, qualquer prestígio para fora de um campo que o não tem - ainda que isto possa ser injusto para esses estudiosos e para o que estudam. É esta, na verdade, ainda hoje a situação das literaturas de língua portuguesa no mundo, apesar de a língua portuguesa estar em vésperas de ser uma das numericamente mais importantes, e de a literatura brasileira corresponder sem dúvida, como uma literatura, ao conjunto das diversas literaturas americanas de língua espanhola, cujo estudo é individualmente, nos Estados Unidos da América, posto como que em pé de igualdade com ela, assim como se se pudesse razoavelmente falar de literatura guatemalteca ou uruguaia, sem ser ao nível de, brasileiramente, se falar de literatura do Nordeste, ou 
literatura de Minas Gerais (ainda que o Brasil tenha sempre possuído um centro de gravidade no Rio de Janeiro, que faltou e falta analogamente àquelas literaturas hispânicas nacionais). Assim, em termos de LatinoAmérica, um Machado de Assis pode erradamente ser considerado no plano de qualquer grande escritor aparecido em Hispano-América, em termos nacionais - o que é um grosseiro erro de perspectiva do mito americano do que seja especialização literária.

Reciprocamente, no plano nacional interno, o grande escritor excepcional é vítima também de erros de perspectiva. Muito raramente, e sempre com secreta humildade (e esta quantas vezes se disfarça de uma intensa arrogância nacionalista e até patrioteira!), é ele posto em pé de igualdade com os grandes nomes de outras culturas, aos quais, por tácita definição, se reconhece uma grandeza que, no fundo, ao nacional se nega. E o facto de, como hoje sucede no Brasil, existir na crítica e na atenção literárias uma obsessiva preocupação com a literatura brasileira enquanto tal, longe de ser apenas um sintoma (que é) de confiança nela, constitui como que um modo de, pela supressão das outras literaturas, tentar suprimir a realidade de um complexo absurdo mas que, lamentavelmente, assim existe e mesmo se perpetua. Nestas condições, um Machado de Assis é considerado o maior escritor brasileiro (e só um Guimarães Rosa poderá rivalizar com ele, em originalidade e em profundidade universais), como se, para tal, necessário fosse não o ver num contexto internacional e comparativista. Quando, na crítica, esse contexto aflora, é realmente para apontar-se (às vezes com superficialidade escolarmente inaceitável) o que ele deve às grandes culturas suas contemporâneas, como se algum grande escritor, mesmo os maiores génios da humanidade, não fosse passivo de tais observações e achados, ou como se isso significasse, seguramente, um sinal de particular grandeza. Esquece-se, quer no afã nacionalista, quer no afã de lavar complexos despropositados, que todo o grande escritor está simultaneamente dentro e acima da literatura a que pertence - e não só porque a crítica nacional ou internacional venha a reconhecer-lhe essa categoria: mas porque ele a reconheceu em si mesmo e culturalmente assim se formou, para melhor criar à sua própria medida, antes e independentemente do reconhecimento de que tenha sido objeto.

E isto nos coloca no centro da questão da peculiar grandeza do grande escritor de "pequenas" culturas. Ciente ele mesmo de que o seu meio o condiciona terrivelmente (o que evidentemente é mais sensível lá onde não existam as condições de uma intensa vida intelectual e literária, em 
simultâneas qualidade, quantidade e confiante prestígio, mas não menos se dá em qualquer outro meio), ele tenderá a exigir de si próprio o que o próprio meio não exigiria em tal escala, e terá ou buscará ter uma cultura e uma lucidez crítica que, equivalentemente, não existe nos seus pares das grandes culturas. Estes, na maioria das vezes, não necessitam mais que deixar-se flutuar na deriva do seu ambiente cultural. Por outro lado, essa exigência farse-á sentir por uma forma muito específica onde o escritor se veja aparecido numa cultura "nova", em busca da sua "expressão". Todavia, tal forma específica assume aspectos contraditórios, ou assumiu-os, no caso das nações nascidas sob o signo das revoluções liberais românticas (ou que as ideologias românticas imediatamente adaptariam aos seus fins oligárquicos de aristocratização das burguesias), como foi o caso do Brasil, e não foi o dos Estados Unidos (nascidos do "governo civil" de Locke e do "contrato social" de Rousseau). Todas as fases do revolucionarismo ideológico estético, mesmo nas grandes culturas (onde aliás tiveram a origem), sempre se proclamaram "novas" culturas, por oposição aos hábitos estéticos precedentes - e poucas revoluções estéticas se pretenderam tão radicalmente "novas" como o Romantismo se imaginou (não quer isto dizer que o tenha sido e em toda a gente). Para tal, havia que recorrer a tudo o que fosse anterior, e garantia fosse de raízes não manchadas pela sociedade aristocrática, centralista, absolutista, etc., a que mesmo o mais reacionário dos Romantismos não deixava de querer disputar a primazia social. Para nações que se libertavam de um passado colonial (ao preço de as suas oligarquias se organizarem na dependência das grandes potências), a adaptação da ideologia romântica forçava a especiais contradições culturais. Com efeito, antes das grandes vagas migratórias que as oligarquias atraíram por necessidade de mão de obra, o passado longínquo estava necessariamente na antiga mãe-pátria; e, no início da independência, coincidentes com os pressupostos românticos, isto era ao mesmo tempo uma imposição e uma impossibilidade. A cultura tinha de procurar-se a si mesma na ambiência local. E esta tinha, na verdade, de ser descoberta, porque as tradições literárias europeias não lhe davam qualquer prioridade particular. O Romantismo, porém, oferecia soluções perigosamente prontas, com o seu culto do pitoresco, do exótico, do ancestral mítico. E, assim, para ser-se nacional e fundar uma literatura "nacional", o que convinha era uma pessoa extasiar-se ante a beleza específica da paisagem nacional (incluindo as espécies botânicas), como se todas as paisagens nacionais não fossem igualmente belas para os "ufanismos" de qualquer parte; procurar descrever 
aqueles costumes que fossem exclusivamente e caracteristicamente nacionais (como se os costumes não fossem, em toda a parte, variações de padrões humanos universais); e descobrir, nos escritores "nacionais", uma vontade de nacionalismo, ainda que historicamente improvável ou esteticamente indesejável (o que deu a suprema contradição, no Brasil, de os românticos admirarem os árcades que, como românticos, deveriam ter detestado). Que a realidade da vida quotidiana pudesse ser uma fonte mais autêntica e mais profunda para a investigação das peculiaridades "nacionais" (ou seja, para a condição brasileira, num dado contexto psicossocial, historicamente definido, e não idealizadamente imaginado num passado mítico ou num presente emasculado de dramas transcendentes), eis o que suspeitosamente seria considerado, e tem-no sido: Machado longamente pagou criticamente o preço de ter buscado ser "brasileiro" por dentro, quando não mais se lhe pedia senão que o fosse por fora. O preço de que ele teve plenamente consciência, quando escreveu o seu célebre ensaio (e tão contraditoriamente entendido segundo as conveniências polémicas imediatas, por muito virtuosas que tenham sido) sobre "instinto de nacionalidade", ao tempo em que, timidamente, aparecia como romancista, adentro dos esquemas do realismo romântico.

Uma das infelicidades de ser-se um grande escritor de uma literatura que se tem por secundária está em que os críticos tendem sempre a aceitar, para ela, os esquemas periodológicos das "grandes", sem se informarem devidamente sobre o que tais esquemas possam realmente significar, e muitas vezes com um só elementar conhecimento indireto, colhido ao nível do manual. Ou, pior, sem se interrogarem o que os ismos que os fascinam e esmagam realmente foram e quando. Tem-se dito que Machado de Assis é um realista, sobretudo porque, periodologicamente, os seus romances coincidem com o que se convencionou, sem crítica, chamar o período realista. Acontece, porém, que ele é, por certo, um realista, mas não por esta razão. Os "realistas" foram, na verdade, os naturalistas, quando se opuseram ao realismo romântico que eles consideravam deformar idealizadamente a realidade social e trair uma concepção científica e polêmica do realismo como arte. Que eles se tenham chamado a si mesmos de "realistas", para roubarem a realidade aos realistas românticos, eis o que foi problema polémico deles - infelizmente perene na confusão mental das histórias literárias. Os realistas românticos foram complexamente o que podemos simplificar em duas tendências principais: uma, inerente ao próprio Romantismo, o que demasiado se esquece (o Romantismo queria-se 
"natural", por oposição ao convencionalismo literário setecentista), e outra de reação à fantasia e ao historicismo românticos (contracorrente que o Romantismo internacional teve desde os seus inícios, e que, nos meados do século XIX, assumiu a supremacia, participando da liquidação dos sonhos românticos libertários, inimigos da estabilização burguesa que se desenhava: época vitoriana, Segundo Império francês, Germânia biedermeier, Portugal constitucionalista, governo pessoal do imperador d. Pedro II). Dentro do "realismo romântico" (que teve as suas horas de intervencionismo político de base humanitarista) foi que se desenvolveu o realismo estético de Flaubert, em quem os naturalistas se não esqueceram de ver um precursor. E ele era-o numa crítica social de raiz estética, que usava do romance como forma oponível ao informe e ao medíocre do mundo burguês. Mas não o era, por as suas convicções de artista e o seu pessimismo moral the vedarem uma confiança na ciência ou nas analogias da ciência e da arte (que já Balzac sentira) de que os naturalistas vieram a fazer as bases extraestéticas do seu credo artístico. Partilhava, porém, com os seus sucessores naturalistas, como com os seus contemporâneos do realismo romântico, a ideia de uma missão ética da arte, porém acima do conformismo com quaisquer padrões de moral normativa ou com mistificações de idealização social. A reação do realismo estético contra as idealizações do realismo romântico (em que ambientes, cenários, tipos populares, caracterizações irónicas das personagens eram realistas, mas o comportamento destas ou a trama romanesca o não eram, mas adequadas ao conformismo da burguesia triunfante pela já associação com as aristocracias tradicionais) veio a confundir-se com a reação contra os "excessos" e as simplificações do naturalismo violento. E é por isso mesmo que, nas literaturas ocidentais, nós vemos o psicologismo, o esteticismo, e até um retorno à fantasia dos românticos, aparecerem lado a lado com o naturalismo e logo se oporem a ele. Não é por acaso que a última fase de Machado de Assis é contemporânea de Henry James, Paul Bourget, Villiers de I'Isle Adam, Barbey d'Aurevilly, Huysmans, Checov. Neste contexto, Machado de Assis, tendo iniciado uma carreira de realista romântico, segundo os padrões convencionais (recorde-se que um Brunetière punha Octave Feuillet ao lado de Flaubert, como toda a crítica do tempo pôs a Fanny de Ernest Feydeau a par da Madame Bovary), dá início à sua última fase, não como um realista romântico que se "psicologiza", mas como um autor inteiramente afinado pelo seu tempo internacional, que se liberta. Não é também por acaso, ou por gosto da ironia, que a libertação se processa com uma obra realista, despojada de idealizações, estruturada sob o signo da 
fantasia, mas supostamente escrita por um defunto. Brás Cubas é o símbolo de uma libertação que se vinha processando gradualmente em alguns contos (está ainda por fazer um estudo sistemático deles, que muitos garantiriam, só por si, um lugar na literatura universal a Machado), e mesmo nas entrelinhas dos romances que ele ia regularmente oferecendo ao seu público, e a cuja regularidade a aparição de Memórias póstumas não escapou. Que esta regularidade tenha desaparecido depois, nos mais quase trinta anos em que escreveu os restantes romances, pode ter várias explicações, mas por certo que uma delas é a que aquele símbolo aponta: o autor saíra do mundo de produzir romances para o seu público (que era o de todos os outros escritores do Brasil do tempo), e ingressara no mundo de escrevê-los à escala da sua liberdade de "ressuscitado" pela arte do romance, no mais alto e original nível do seu tempo universal. Que ele tinha plena consciência disto (ainda que não do que iria suceder-lhe com a estrutura dos que viriam depois) é claramente expresso nas linhas "ao leitor" assinadas por Brás Cubas, em que é dito ficar, pela sua estrutura, o livro privado da simpatia dos "graves" e dos "frívolos" por opostas razões, e no "prólogo" aposto por Machado, quando a série já estava em marcha, e em que ironicamente menciona a pergunta de Capistrano de Abreu: "as Memórias póstumas de Brás Cubas são um romance?". Realista, como vemos, ele foi-o, mas não por coincidência de nomenclatura fora de propósito, mas sim como realista estético-psicologístico que criava a sua própria forma romanesca, fora das estruturas convencionais do realismo romântico e do naturalismo que as prolongou.

O próprio psicologismo tão decantado requer, para uma compreensão estético-estrutural da série final, algumas precisões. Porque, na verdade, não é nunca, em nenhum dos cinco romances, um analitismo descritivo de intenções, volições, motivações, etc., feito por um autor omnisciente, como o é na maioria dos contemporâneos universais de Machado, de tendência psicologística. Muito pelo contrário, é quase sempre e magistralmente uma proposta continuamente renovada de entendimento psicológico, uma hipótese constantemente desmentida pelos factos de comportamento das personagens, e constantemente reajustada, sem que nunca se chegue a mais que um retrato angustiosamente ambíguo. De livro para livro, a série é a demonstração estética, de todos os pontos de vista possíveis, da impossibilidade humana de conhecer-se alguém a si mesmo ou aos outros, e uma análise implacável, e metodicamente sistemática, da capacidade humana para substituir a mistificação à realidade. Assim sendo, e sendo a opinião de 
Machado de Assis essa (que igualmente aterraria os "graves" e conspícuos, e os "frívolos" não mais superficiais do que aqueles), a única forma de superar o impasse que a sua inteligência e a literatura do seu tempo lhe revelavam era exatamente o que ele fez: criar obras de arte inter-relacionadas (o que é também o desmentido ao preconceito realista de que cada romance possa ser uma obra em si mesma, ainda que seja, per se, uma obra de arte acabada) que mostrassem, como um jogo de espelhos, a ambiguidade fundamental da consciência humana, sem lhe darem a ilusão de que os espelhos se substituíam favoravelmente e comodamente à vida (o que foi a ilusão do esteticismo): à ambiguidade da vida e da consciência não se sobrepunha a solução da arte, mas precisamente o contrário - a arte simbolizaria e representaria uma dupla ambiguidade que é a da vida e a da existência dela mesma como arte. Entre 1880, quando Brás Cubas apareceu na Revista Brasileira, e 1907, quando perto da morte ele datou o Memorial de Aires, poucos romancistas foram tão modernos e tão nossos contemporâneos como esse homem que, cautelosamente, se impôs primeiro ao respeito público de seu país, para depois fazer o que muito bem lhe apetecia na obra que é, escrita em sequência de um livro escrito por um "defunto", o seu testamento espiritual.

Como foi isto feito? Comecemos por observar uma característica imediatamente aparente da técnica romanesca: a perfeita e simétrica alternância da forma da narração:

\begin{tabular}{|c|c|c|c|}
\hline Brás Cubas & \multicolumn{3}{|c|}{ narrado na $1^{\mathrm{a}}$ pessoa } \\
\hline Quincas Borba & $"$ & $" 3^{\mathrm{a}}$ & $"$ \\
\hline Dom Casmurro & $"$ & $" 1^{\mathrm{a}}$ & $"$ \\
\hline Esaú e Jacob & $"$ & $" 3^{\mathrm{a}}$ & $"$ \\
\hline M. de Aires & $"$ & $" 1^{\mathrm{a}}$ & $"$ \\
\hline
\end{tabular}

É evidente uma simetria concreta de que Dom Casmurro é o eixo central. Mas consideremos agora quem narra, e detenhamo-nos na narrativa pessoal que três vezes é explorada. Brás Cubas narra a sua vida do ponto de vista do "defunto", ou seja, do homem que tem uma perspectiva total, completa, e omnisciente, mas também, pela sua qualidade de morte, teoreticamente desapegada da vida: a sátira profunda do impossível fundamental - a objetividade só é possível (e mesmo assim... muitas páginas do livro são uma irónica denúncia que até na morte isso seria impossível) nas "memórias póstumas" que só podem ser uma ficção estética. Em Dom 
Casmurro, é Bentinho, o protagonista, quem nos narra memorialisticamente a sua vida. Mas Bentinho é parte altamente interessada na própria história que ele nos narra em conformidade com a sua personalidade, a sua consciência de culpa, a sua curiosidade de saber de si mesmo e de Capitu, o seu desejo de tornar-nos cúmplices da sua autojustificação. Saímos do irreal irônico de Brás Cubas, para a ironia trágica da realidade de Bentinho: e o preço de termos passado da ficção do irreal julgando a vida, para a ficção do real, é o de perder-se a omnisciência, ou de ficar-se amarrado à omnisciência maligna do narrado. Em Memorial de Aires, supostamente fragmento do diário do narrador, não temos nem um morto nem um vivo a narrarem-nos as suas vidas, e ansiosamente buscando, um e outro afinal, a nossa complacência. Temos a complacência mesma: porque o narrador é apenas uma testemunha do que narra e de que não é (ou não se apresenta ser) protagonista. Passámos ao último grau de ângulo pessoal, mas, ao passarmos, perdemos a virtude da participação: Aires é a testemunha que só pode oferecer compreensão e benevolência para com os dramas humanos, na medida em que se conserve encerrado no solipsismo da sua bondade. Que ele ofereceu benevolência e compreensão aos protagonistas, ao lidar com eles, transparece das páginas das suas notas: mas o que nós temos é apenas o registo melancólico de quão pouco isso altera o destino que cada um cria para si mesmo.

Voltamos ao pequenino quadro. Dom Casmurro está nele como o eixo também de dois pares romanescos: Brás Cubas com Quincas Borba que o prolonga, e Memorial de Aires com Esaú e Jacob que, como é dito na "Advertência" inicial, era o último dos cadernos do "memorial" e se diferençava deles por ser uma "narrativa" em que Aires se fazia indiretamente aparecer. Ele é o elo de ligação entre os dois pares, e mais profundamente do que possa parecer. Em 1899, no prólogo da terceira edição de Quincas Borba, Machado diz o seguinte:

[...] um amigo e confrade ilustre tem teimado comigo para que dê a este livro o seguimento de outro. - Com as Memórias póstumas de Brás Cubas, donde este proveio, fará você uma trilogia, e a Sofia de Quincas Borba ocupará exclusivamente a terceira parte -. Algum tempo cuidei que podia ser, mas relendo estas páginas concluo que não. A Sofia está aqui toda. Continuá-la seria repeti-la, e acaso repetir o mesmo seria pecado. Creio que foi assim que me tacharam este e alguns livros que vim compondo pelo tempo fora no silêncio da minha vida. 
E isto era dito, quando Dom Casmurro era publicado e já estaria escrito: nenhuma Sofia se repete, a não ser como outra personagem, tal como nenhum de nós se repete fora da nossa vida mortal - a repetição de Sofia teria de ser diversa. É Capitu. E não porque seja pecado repetir, nos termos em que a crítica superficial ou adversa não entenda a originalidade com que um grande escritor se "repete", mas porque a outra repetição, a de um ser, por continuação, é impossível ao criador consciente de que nada se continua, neste mundo, senão noutro contexto, e sob outro avatar, para quem tenha os olhos abertos para a prisão das normalidades num contexto vital ou estático.

Deste modo, os três primeiros romances constituem uma trilogia, a que um par veio juntar-se. Mas, para lá das simetrias que já observámos, não haverá mais que torne estes dois grupos ainda mais intimamente relacionados? Como se passa de Dom Casmurro, contado pelo protagonista, para Esaú e Jacob, contado impessoalmente por Aires? E quem realmente conta a história de Quincas Borba?

Quincas Borba, cujo herói é diretamente Rubião, é contado na $3^{\text {a }}$ pessoa, por alguém que é como que o autor, um autor que, nas pequenas artimanhas do seu ofício, no gosto da digressão irónica, no prazer de referir casos ou citar paralelos cultos, que parecem não ter que ver com a história, se não distingue do Brás Cubas póstumo, de Bentinho, ou de Aires (impessoal ou pessoalmente memorialista). Um autor que se não esconde de ser comum a todos os romances, por não acreditar na ficção de ficção, que é o autor pretender-se outra pessoa, quando escreve. Esse autor aparece enquanto tal precisamente no livro seguinte às "memórias póstumas": é o autor liberto por elas, mas de modo algum regressando à narrativa tradicional realista como estrutura, pois que não assume uma posição invisível, nem, por outro lado, se apresenta como omnisciente. É como se as personagens nasçam e existam na sua obra, à medida que ela é escrita, mas não como se diz que personagens impõem a própria existência a um autor que vai conduzido por elas. Não. As personagens de Machado de Assis, nos últimos romances, nem o conduzem, nem são conduzidas - e pela simples razão de que a ação dos romances é o ato de eles serem escritos. Isso é patente mesmo no romance que melhor finge usar da ficção de uma personagem escrevendo, que é o Memorial de Aires. Contudo, tal não é patente pela razão demasiado fácil, e já várias vezes proposta, de Aires ser um alter-ego do próprio Machado de Assis chegando a contas finais com a vida. Pelo contrário, é-o, porque Machado teve arte de nos iludir com a semelhança entre o velho diplomata, grã-fino e viajado, e o ar académico e conselheiral que ele próprio assumiu numa contraditória 
identificação com os padrões bem-pensantes e educados socialmente do seu tempo, como se ele realmente fosse, no fundo da sua personalidade de escritor, um daqueles "graves" de quem se ria no citado prefácio dirigido ao leitor por Brás Cubas. Por isso, na simetria do conjunto, ao ter de regressar à narrativa na $3^{\mathrm{a}}$ pessoa, ele se serviu de Aires para a narrativa impessoal, do que avisa na citada Advertência. Assim, vemos que os dois romances iniciais, constituindo pela repetição de personagens e pela trama romanesca um todo, são escritos pelo "Autor" (na ficção de um "defunto", e na ficção dele mesmo), enquanto os dois últimos são escritos por Aires (na ficção de autor, e na ficção de ser ele mesmo). E uma mais profunda simetria nos aparece, de que o eixo é a narrativa de Bentinho enquanto autor e também protagonista (que Aires não é). Esta simetria é ainda mais subtilizada, se notarmos que o "publicador" não se coíbe de intervir na narrativa de Aires, em Esaú e Jacob.

Tudo isto, no tempo coberto pelos romances, vai desde os primeiros anos do século (o tempo mais antigo em Brás Cubas), até 1889 (que é a data fictícia das últimas páginas do memorial) e aos primeiros anos da República (em Esaú e Jacob). Dentro de cada um dos romances, há um constante vai e vem do tempo, com que eles se cobrem e recobrem na cronologia histórica, e com que, cada um por si, avança mais ou menos na relativa distância da data em que foram escritos. O conjunto, porém, cobre o século XIX do Brasil, centrado no Rio de Janeiro, e mais do que nenhum outro esta estrita localização é verídica para Dom Casmurro. Com tudo o que fica dito, poderia afirmar-se que os cinco romances são, em termos das livres formas romanescas contemporâneas, um único romance experimental - um "quinteto carioca", se recordarmos a brilhante criação de Lawrence Durrell, The Alexandria Quartet, em quatro partes publicadas em 1957-60. Mas um quinteto incomparavelmente melhor e mais subtilmente entretecido do que o quarteto de tão grande ressonância mundial. Uma análise minuciosa dos paralelos e contrastes internos entre os cinco romances, adentro do esquema que estabelecemos, e que não cabe aqui, mais amplamente confirmaria a extraordinária criação unitária que profundamente significou.

Como foi isto possível numa literatura que "nascia" (quando Machado começou a sua carreira literária, o Brasil mal tem trinta anos de existência) e que procurava a sua "realidade"? Porque os grandes escritores são, em qualquer parte e em qualquer época, aqueles que escrevem com a história da sua língua e a realidade linguística dela na linguagem que criam, e com toda a literatura universal na cultura que adquirem. Quem procura realidades e quem nasce são as literaturas nas cabeças dos críticos. Os escritores como 
Machado de Assis encontram, e escrevem. E as literaturas, depois, não têm outro remédio, se quiserem sê-lo, senão aceitá-los como eles foram - e à realidade, como eles a viram. Pouco importa saber se o "quinteto carioca" é um fiel retrato do Brasil e do Rio de Janeiro do século XIX, porque, suprema ironia estética, o retrato íntimo deles, na sua universal humanidade, será para sempre o que desenhou, com refinada e desencantada amargura, aquele cidadão urbano, hiper-civilizado na sensibilidade e na cultura, de origem humilde, presidente de academia, mulato, de barba e "pince-nez", e que não precisou de viajar, ao contrário de Aires, nem de ter uma vida tumultuosa, ao contrário dos românticos "oficiais", para conhecer exatamente, e sem ilusões, o mundo por dentro e por fora.

Universidade de Wisconsin, Madison, Julho de 1969.

\section{Referência}

SANTIAGO, Silviano. Uma literatura nos trópicos: ensaios sobre dependência cultural. 2. ed. Rio de Janeiro: Rocco, 2000. 